\title{
Sistemik Hastalığı Olmayan Obstrüktif Uyku Apne Sendromlu Hastalarda Ani Kardiyak Ölüm Riskinde Kardiyak Repolarizasyon Indeksinin Rolü
}

\section{The Role of Cardiac Repolarization Index for Sudden Cardiac Death Risk in Patients with Obstructive Sleep Apnea Syndrome without any Systemic Disesae}

\author{
Kezban Aslan, Durmuş Yıldıray Şahin*, Turgay Demir, Ahmet Evlice, Gülşah Şeydaoğulları* * \\ Çukurova Üniversitesi Tıp Fakültesi, Nöroloji Anabilim Dalı, Adana, Türkiye \\ *Çukurova Üniversitesi Tıp Fakültesi, Kardiyoloji Anabilim Dalı, Adana, Türkiye \\ **Çukurova Üniversitesi Tıp Fakültesi, Biyoistatistik Anabilim Dalı, Adana, Türkiye
}

\section{Özet}

Giriş: Obstrüktif uyku apne sendromlu (OUAS) hastalarda ani kardiyak ölüm riskinin yüksek olduğu bilinmektedir. Bu çalışmada hipertansiyon $(\mathrm{HT})$, diyabet (DM), tiroid, kalp hastalığı, elektrolit bozukluğu gibi kronik sistemik hastalığı olmayan hastalarda kardiyak repolarizasyon indeksine bakılarak ani kardiyak ölüm ilişkisi irdelenmek istenmiştir.

Gereç ve Yöntem: Çalışmaya, Ocak 2008- Ocak 2010 tarihleri arasında, horlama, tanıklı apne yakınmaları gereği OUAS ön tanı ile polisomnografik

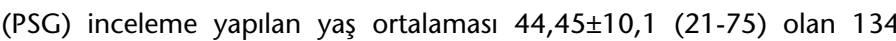
erkek, 36 kadın toplam 170 hasta dahil edilmiştir. PSG öncesi 12 kanallı elektrokardiyografik kayıtları yapılmış ve QT minimum, QT maksimum ve QT dispersiyonları hesaplanmıştır.

Bulgular: Hastalar apne-hipopne indeksine ( $\mathrm{AHI}$ ) göre dört gruba ayrılmıştır; $\mathrm{AHI} \leq 5,5<\mathrm{AHI} \leq 15,15<\mathrm{AHI}<30$, ve $\mathrm{AHI} \geq 30$. Ortalama QTD $3,8 \pm 2(0,40-9,7) \mathrm{msn}$, normal olan grupta $(\mathrm{AHI} \leq 5) 3,5 \pm 1,8(0,6-8,9) \mathrm{msn}$, ağır olan grupta $(\mathrm{AHI} \geq 30)$ ise 4,5 $\pm 1,9(0,4-9,7)$ msn olarak belirlenmiştir $(p=0,010)$. Hastalarda AHI arttıkça, QTD artmış olarak belirlenmiştir.

Sonuç: Kronik sistemik hastalığı olmayan OUAS hastalarının QT uzamas nedeni ile ani kardiyak ölüm riskleri vardır. (JTSM 2014;2:46-50)

Anahtar Kelimeler: Ani kardiyak ölüm, OUAS, QT dispersiyonu

\section{Summary}

Introduction: Obstructive sleep apnea syndrome (OSAS) is associated with sudden cardiac death (SCD). In this study we aimed to evaluate the ventricular recovery time in OSAS patients without chronic systemic diseases, such as hypertension, diabetes, thyroid dysfunction, electrolyte imbalance, cardiac disease and the relationship of OSAS with SCD.

Materials and Methods: In the study, between January 2008-January 2010, we analyzed 170 patientswith a mean age of $44.45 \pm 10.1(21-75)$ years, who were clinically suspected of having OSAS. Following overnight polysomnography (PSG), 12 lead surface electrocardiogram (ECG), recordings were perforned and QT minimum, QT maximum and QT dispersion were computed from ECG.

Results: The patients were divided into to the following 4 groups; $\mathrm{AHI}$ (apnea-hypopnea index) $\leq 5,5<\mathrm{AHI} \leq 15,15<\mathrm{AHI}<30$, and $\mathrm{AHI} \geq 30$. The mean QTD was 3.8 $\pm 2(0.40-9.7) \mathrm{msn}$ in all patients and 3.5 $\pm 1.8(0.6-8.9)$ $\mathrm{msn}$ in normal group (AHI $\leq 5)$, and $4.5 \pm 1.9(0.4-9.7) \mathrm{msn}$ in severe group (AHI 230 ). It is shown that QTD increases significanty when AHI rises. Discussion: We showed that the patients with OSAS without chronic systemic disorder have higher SCD risks due to increased QT dispersion. (JTSM 2014;2:46-50)

Key Words: Sudden cardiac death, OSAS, QT dispersion 


\section{Giriş}

Obstrüktif uyku apne sendromu (OUAS), uyku sırasında üst solunum yolunun tekrarlayıcı tam ya da kısmi tıkanıklıkları ve buna eşlik eden intermitant hipoksemi ve reaktif uyanma reaksiyonları ile karakterize bir hastalıktır. Solunumsal olaylar sırasında gelişen kronik intermitant hipoksemi, oksidatif stres, otonomik disfonksiyon $(1,2)$, endotel disfonksiyon (3), intratorasik basınç dalgalanmaları (4), metabolik disregülasyon $(5,6)$ ve inflamasyona (5) neden olarak kardiyovasküler hastalıkların gelişmesine neden olmaktadır $(4,7)$.

OUAS hastalarında kardiyovasküler hastalık riski yüksek olduğu bilinmektedir. Daha önce yapılan çalışmalarda uyku apne sendromu hastalar ile kardiyak aritmiler, iletim anormallikleri arasındaki ilişki gösterilmiştir $(2,3,8)$. Uyku Kalp Sağlığı çalışma grubu OUAS'ı hastalarda, diğer risk faktörlerinden bağımsız olarak, kalp yetersizliği riskini 2,38 kez arttığını gösterilmiştir (9). Yine OUAS hastalarında; kalp hızında (HR), kalp hızı düzeltme zaman (HRR-1), QTc ve $P$ dalga süresinde ve dipersiyonunda artış olduğu gösterilmiştir (3,10-12).

Diyabet ya da hipertansiyon gibi kronik hastalıklar, gerek otonomik disfonksiyon, gerek atrio-ventriküler fonksiyonel değişikliklere neden olarak kardiyovasküler hastalıklar için önemli risk faktörü oluşturduğu bilinmektedir. Bu çalışmada, diyabet, hipertansiyon, tiroid gibi sistemik hastalığı olmayan hastalarda OUAS'ın kardiyak repolarizasyon üzerindeki rolü araştırılmak istenmiştir.

\section{Gereç ve Yöntem}

Çalışmaya, Ocak 2008- Ocak 2010 tarihleri arasında, Çukurova Üniversitesi Tıp Fakültesi Nöroloji Bölümü Uyku Polikliniği'ne baş vuran; horlama, tanıklı apne, gündüz aşırı uykululuk gibi yakınmaları olup OUAS ön tanısı ile polisomnografi (PSG) incelemesi yapılan hastalar dahil edilmiştir. Diabet, hipertansiyon (HT), aterosklerotik kalp hastalığı, atrifal fibrilasyon, atrioventriküler blok, kardiyak pil, kardiyomyopati, konjestif kalp yetmezliği, ritim düzenleyici ilaç kullanımı, serebrovasküler hastalık tanısı olan, takip edilen ya da başvuru sırasında yapılan muayene ve incelemeler sonucunda ilk kez diyabet ya da hipertansiyon tanısı alan hastalar çalışma dışı bırakılmışlardır.

\section{Uyku Çalışması}

Hastaların tamamı uyku polikliniğine gündüz aşırı uykululuk, horlama yakınması ile başvurmuş ve tüm gece polisomnografi (PSG) incelemesi yapılmıştır. Tüm gece PSG incelemesi kompüterize sistem (Kommet, Grasstelefaktör) ile yapılmış ve kayıtlamada şu parametreler kullanılmıştır; elektrookülogram (2 kanal), elektroensefalogram (6 kanal), sub-mental kas elektromyogramı ( 2 kanal), her iki bacak anterior tibial kas elektro myogramı (2 kanal), elektro kardiogram (1 kanal), hava akımı (oro-nasal basıç ayarlı- kanül), göğüs ve abdominal hareketleri solunum indüktans pletismografi ( 2 kanal) ve parmak problupulse oksimetri ile arterial oksihemoglobin saturasyonu ( $\mathrm{SaO} 2: 1$ kanal). Kayıtlamalar $10 \mathrm{~mm} / \mathrm{s}$ süpürme hızı ile yapılmıştır. Uyku evrelemeleri ve apne, hipopne skorlamaları AASM (American Academy of Sleep Medicine) 2007 kurallarına göre yapılmıştır (13). Apne, hava akımının $\geq 10$ sn süre ile termal sensör tepe sinyalinde bazal genliğe göre $\% 90$ veya daha fazla düşme olarak tanımlanmıştır. Hipopne, nazal kanül sinyal genliğinde bazale göre $\geq \% 50$ azalma (hava akımı sinyali, göğüs ya da abdominal sinyaller ) ve oksijen saturasyonunda bazale göre $\geq \% 3$ düşme ile birlikte buna eşlik eden uyanıklık reaksiyonları olarak kabul edilmiştir.

\section{Elektrokardiyografik (EKG) Değerlendirme}

PSG incelemesi öncesi hastalar $20 \mathrm{dk}$ istirahat sonrası supin pozisyonunda iken kağıt hız ve özelliği $50 \mathrm{~mm} / \mathrm{sn}$ ve $2 \mathrm{mV} / \mathrm{cm}$ olan 12 kanallı elektrokardiyografik cihazı ile kayıtları yapılmıştır. EKG değerlendirmeleri, olgular hakkında klinik ve laboratuvar sonuçları konusunda kör olan kardiyoloji uzmanı tarafından yapıldı. Olguların Q-T (QT max c, QT min c, QT dipersiyonu [QTD]) intervalleri manüel hesaplandı.

Olgular apne hipopne indeksine (AHI) göre 4 gruba ayrıldı (grup 1: $\mathrm{AHI} \leq 5$, grup 2: $5<\mathrm{AHI} \leq 15$, grup 3: $15<\mathrm{AHI}<30$, grup 4: $\mathrm{AHI} \geq 30$ ). Hastaların yaş, cinsiyet, vücut kitle indeksi (VKI), uyku mikrostrüktürleri, minumum $\mathrm{O}_{2}$ saturasyonu, minimum kalp atım hızı, maksimum kalp atım hız sonuçları dört grup içerisinde karşılaştırıldı.

\section{İstatistiksel Analiz}

Tüm değişkenler için normaliteler kontrol edildi. Data bilgi dağılımı normal olmayan sonuçlar için uygun non-parametrik testler seçildi. Gruplar arası normal dağılımı karşılaştırmak için "student t test" ve "one way ANOVA" ve normal dağılımı olmayan veriler için ise "Mann-Whitney $U$ test" ve "KruskalWallis test" kullanıldı. Gruplar arası katogorik değişkenler için analiz "Chi square test" ya da "Fisher's exact test" uygulandı. Sonuçlar, ortalama \pm standard deviasyon (min-max) olarak verildi. Tüm verilerin istatistiksel analizi SPSS v 20.0 paket programı kullanılarak yapıldı.

\section{Bulgular}

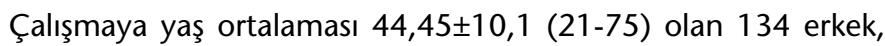
36 kadın toplam 170 hasta dahil edilmiştir. Apne/hipopne indeksi (AHI) sonuçlarına göre hastalar dört gruba ayrılmış ve bu grupların demografik özellikleri ile biyokimyasal sonuçları Tablo1'de verilmiştir.

Tablo 1'de görüldüğü üzere, yaş ortalamasının, erkek cinsiyetinin, VKI'nin 4. grupta istatistiksel olarak daha yüksek oranda olduğu belirlendi. Bununla birlikte HDL grup 1'de yüksek olarak belirlenirken, trigliserid düzeylerinin ağır grupta (grup 4) daha yüksek olduğu saptanmıştır.

Polisomnografik değerlendirmelere göre; gruplar arası, uyku latansı, uyku etkinliği arasında fark yokken, uyku evreleri, minimum $\mathrm{O} 2$ saturasyonu arasında istatistiksel olarak anlamlı düzeyde fark olduğu belirlendi. Kardiyak repolarizasyon indeksi açısından değerlendirildiğinde; QT intervalinin maksimal düzeyinin ve özellikle QT dispersiyon indeksinin AHI yüksek olan hastalarda istatistiksel olarak anlamlı düzeyde arttığı belirlenmiştir. Hastaların AHI arttıkça, QT dispersiyon indeksinin anlamlı düzeyde arttığı saptanmıştır (Tablo 2, Resim 1).

QTD, Tablo $3 a$ ve $3 b^{\prime}$ de görüldüğü üzere sadece $A H I$ $(r=, 247)$ ile pozitif korelasyon içinde olduğu saptandı. Bununla birlikte, AHI'nin QTD yanı sıra, yaş, VKI ile pozitif korelasyon $\left(r=203^{* *}, 415^{* *}\right), \mathrm{HDL}$ ve kayıt sırasında elde edilen minimal $\mathrm{O} 2$ saturasyonu ile negatif korelasyon içinde olduğu $(r=-, 249 * *$, ,$- 833^{* *}$ ) gözlenmiştir. 


\section{Tartışma}

Q-T intervali, elektrokardiyogram (EKG) üzerinde ventriküler depolarizasyon bulgusu ( $Q$ dalgasının başlangıcı) ile repolarizasyonun tamamlandığı ( $T$ dalgasının sonu) an arasındaki süredir. Bu bulgu, potansiyel ventriküler repolarizasyon anormallikleri için belirteçtir. Repolarizasyon anormallikleri ventriküler aritmiler (torsa da pointes) ile ilişkili olup ventriküler fibrilasyon ve ani kardiyak ölüm ile ilişkilendirilmiştir. QT dispersiyon (QTD) çalışmaları bir çok sistemik hastalıklar üzerinde yapılandırılmış ve bu olgulardaki kardiyak aritmi ve ani ölüm olasılıkları arttığı bildirilmiştir (14-17).

QTD, nörolojik hastalıklar ve özellikle atta yatan kardiyak hastalıkların değerlendirilmesinde kullanılmıştır. Örneğin, insuler korteksi tutan serebrovasküler hastalıklarda, olasılıkla sempatik aktivitenin artmış olması nedeni ile QTD uzamış olduğu saptanmıştır (18). Yine subaraknoid kanamalı olgularda serumda artmış katokolamine sekonder uzamış QTD gözlenmiştir (19-21).

Normal popülasyonda ortalama QTD konusu tartışma konusudur. Kohort çalışmaları sonucu QTD'de en anlamlı veri kardiyovasküler hastalıkları olan olgularda saptanmıştır. Örneklemin çok büyük olduğu bu çalışmalar sonunda Q-T intervalinde (>440 msn) uzaması, artmış total mortalite ve kardiyovasküler mortalite ve ani ölümler ile ilişkili bulunmuştur $(17,22)$. QTD'nin normal popülasyonda $\leq 50 \mathrm{msn}$ olması gereklidir (23). Bizim çalışmamızda; tüm hastaların ortalama QTD'si 3,8 $2(0,40-9,7)$ msn olarak belirlendi. Gruplar arası değerlendirildiğinde grup 1 yani normal olarak kabul edilen grupta $3,5 \pm 1,8(0,6-8,9)$ msn, grup $4^{\prime}$ te ise bu oran $4,5 \pm 1,9$
$(0,4-9,7)$ olarak belirlenmiştir $(p=0,010)$. Hastalarda AHI arttıkça, QTD artmış olduğu belirlenmiştir (Tablo 2, Resim 1).

Bilindiği üzere OUAS hastalarda gözlenen aritmi gibi kardiyovasküler hastalıklar; tekrarlayıcı hipoksemi ve reoksijenizasyon, artmış oksidatif stres, inflamasyon ve sempatik aktiviasyona bağlanmıştır (24). Bizim çalışmamızda hastaların hipertansyion, diyabet, tiroid hastalığı gibi hastalıklarının olmaması OUAS'nun QT uzamasında bağımsız risk faktörü

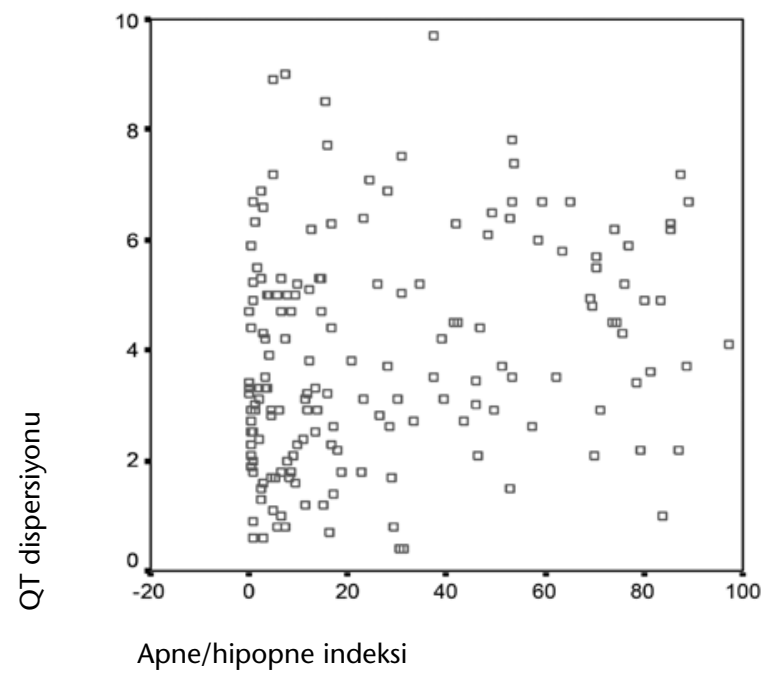

Resim 1. QT dispersiyon ve AHI arasındaki ilişki: AHI arttıkça QTD miktarınında arttığı görülmektedir

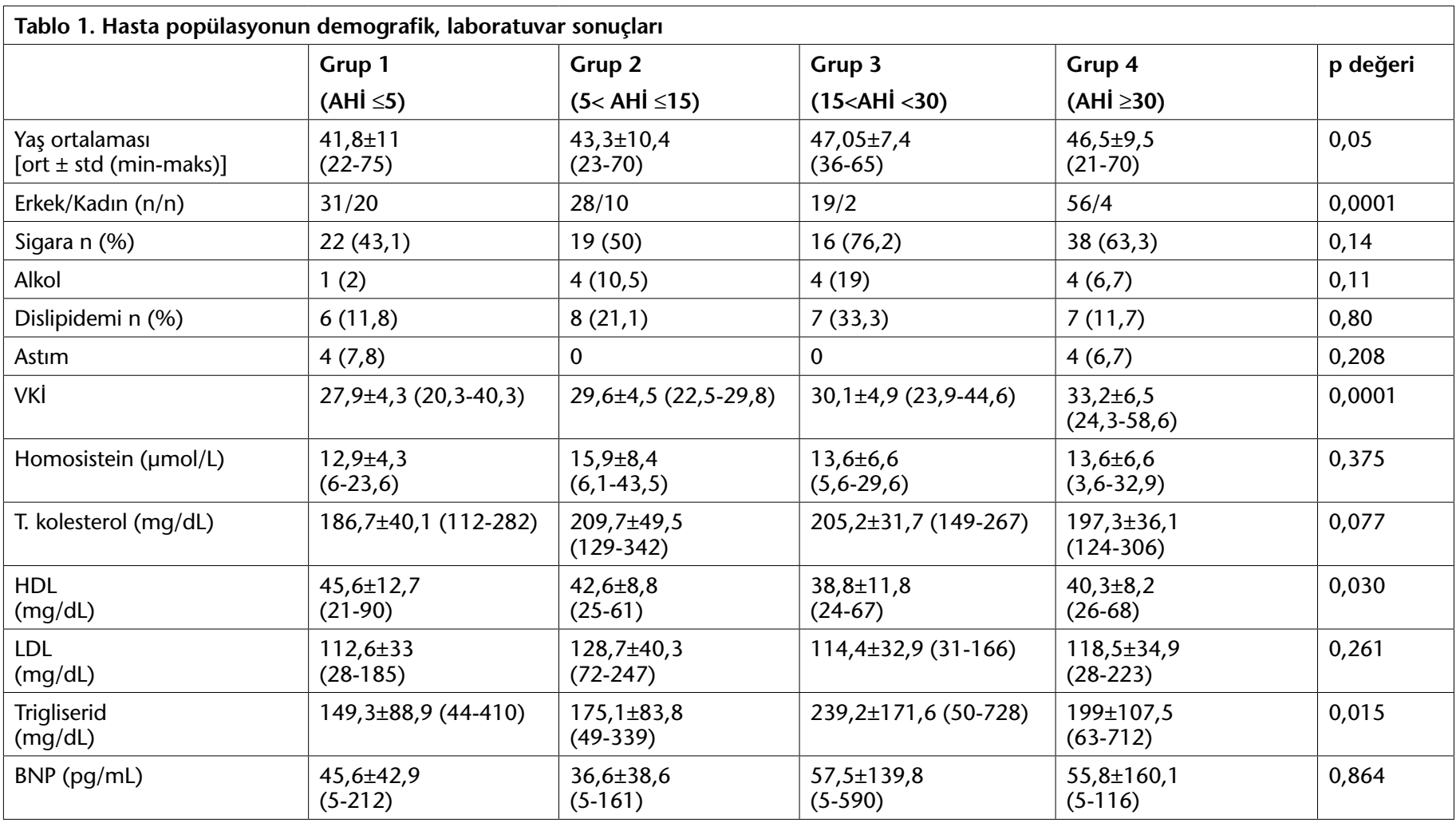

T. Kol: Total kolesterol, HDL: Yüksek dansiteli lipoprotein, LDL: Düşük dansiteli lipoprotein, Trig: Trigliserid, BNP: $\beta$ tipinde, natriüretik peptid 
Aslan K, ve ark.

Sistemik Hastalığı Olmayan Obstrüktif Uyku Apne Sendromlu Hastalarda Ani Kardiyak Ölüm Riskinde Kardiyak Repolarizasyon Indeksinin Rolü

\begin{tabular}{|c|c|c|c|c|c|}
\hline & $\begin{array}{l}\text { Grup } 1 \\
(\mathrm{AHI} \leq 5)\end{array}$ & $\begin{array}{l}\text { Grup } 2 \\
(5<\mathrm{AHI} \leq 15)\end{array}$ & $\begin{array}{l}\text { Grup } 3 \\
(15<\mathrm{AHI}<30)\end{array}$ & $\begin{array}{l}\text { Grup } 4 \\
(\mathrm{AHI} \geq 30)\end{array}$ & $\begin{array}{l}\text { p } \\
\text { değeri }\end{array}$ \\
\hline Uyku latansı (dk) & $26.1 \pm 12.2(1,5-54)$ & $15,4 \pm 11,1(3-56,5)$ & $\begin{array}{c}14 \pm 8,4 \\
(4-35)\end{array}$ & $\begin{array}{l}11,9 \pm 13,1 \\
(1-79,5)\end{array}$ & 0,278 \\
\hline UE (\%) & $89 \pm 10(52,2-99.2)$ & $89,5 \pm 12,8(20,9-99,5)$ & $91,8 \pm 9,2(57,8-99,7)$ & $92,3 \pm 8,6(49,8-98,6)$ & 0,293 \\
\hline N1 (\%) & $\begin{array}{l}10,6 \pm 7,1 \\
(1,1-36,5)\end{array}$ & \begin{tabular}{|l|}
$8,7 \pm 9,3$ \\
$(1-59,4)$
\end{tabular} & $\begin{array}{l}7,8 \pm 4,3 \\
(2,4-18)\end{array}$ & $\begin{array}{l}11,2 \pm 8,7 \\
(1,2-54,8)\end{array}$ & 0,251 \\
\hline N2 (\%) & $59,0 \pm 9,9(26,6-81,3)$ & $59,5 \pm 9,7(40,6-84,4)$ & $64,1 \pm 5,8(54,9-74,4)$ & $75,5 \pm 9,7(34,8-91,3)$ & 0,0001 \\
\hline N3 \% & $\begin{array}{l}17,4 \pm 7,1 \\
(0,3-37,7)\end{array}$ & $\begin{array}{l}19,8 \pm 7,9 \\
(0-34,5)\end{array}$ & $\begin{array}{l}14,6 \pm 7,1 \\
(2,9-30,2)\end{array}$ & $\begin{array}{l}5,1 \pm 6,3 \\
(0-23)\end{array}$ & 0,0001 \\
\hline Min O2 & $\begin{array}{c}91,2 \pm 3,3 \\
(80-98)\end{array}$ & $\begin{array}{c}85,2 \pm 6,0 \\
(70-96)\end{array}$ & $\begin{array}{l}79,4 \pm 10,5 \\
(49-90)\end{array}$ & $\begin{array}{l}64,5 \pm 17,9 \\
(11-88)\end{array}$ & 0,0001 \\
\hline QTmaks. (msn) & $41,7 \pm 3,04(35,9-50,8)$ & $41,8 \pm 2,7(37,1-48,1)$ & $\begin{array}{l}42,4 \pm 2,02 \\
(39-46,3)\end{array}$ & $43,3 \pm 3,4(37,5-54,9)$ & 0,050 \\
\hline QTmin. (msn) & $38,2 \pm 2,7(31,9-45,7)$ & $38,1 \pm 2,9(33,5-44,7)$ & $39,04 \pm 2,4(36,1-43,6)$ & $38,9 \pm 3,1(32,1-45,4)$ & 0,276 \\
\hline QTD (msn) & $\begin{array}{l}3,5 \pm 1,8 \\
(0,6-8,9)\end{array}$ & $\begin{array}{l}3,6 \pm 2,09 \\
(0,80-9)\end{array}$ & $\begin{array}{l}3,3 \pm 1,9 \\
(0,7-7,1)\end{array}$ & $\begin{array}{l}4,5 \pm 1,9 \\
(0,4-9,7)\end{array}$ & 0,010 \\
\hline
\end{tabular}

AHI: Apne/hipopne indeksi, TUS: Total uyku süresi, UE: Uyku etkinliği, N1: Evre 1, N2: Evre 2, N3: Evre 3

\begin{tabular}{|c|c|c|c|c|c|c|c|c|}
\hline & QTD & $\mathrm{AHI}$ & Homosistein & T.Kol. & HDL & LDL & Trig & BPN \\
\hline $\mathrm{QT}_{\mathrm{D}}$ & 1 &, $247^{\star *}$ &,- 026 & ,31 & ,035 &, 065 &, 017 &,- 032 \\
\hline Homosistein &,- 026 &,- 07 & 1 & , 108 &,- 028 & , 153 &,- 051 &,- 150 \\
\hline T.kolesterol & ,31 & ,09 & 108 & 1 & $-0,014$ & $841^{\star *}$ &, $536^{\star *}$ &, $374^{* *}$ \\
\hline LDL & ,06 & ,042 & , 153 &, $841^{\star *}$ & 05 & 1 &, $197^{\star}$ &, $265^{* *}$ \\
\hline Trigliserid & 01 &, $244^{* *}$ &,- 05 &, 536 ** & $485^{\star \star} 1$ & ,197* & 1 &, $385^{* *}$ \\
\hline BNP &,- 03 & $-0,042$ &,- 15 &, $374^{\star *}$ &, $273^{* *}$ & $265^{* *}$ &, $385^{* *}$ & 1 \\
\hline
\end{tabular}

** Korelasyon 0,01 düzeyinde anlamlı, * Korelasyon 0,05 düzeyinde anlamlı , T. Kol: Total kolesterol, HDL: Yüksek dansiteli lipoprotein, LDL: Düşük dansiteli lipoprotein, Trig: Trigliserid, BNP: $\beta$ tipinde, natriüretik peptid

olduğunu düşündürmektedir. Yine QTD, hasta yaşı, kilosu, kayıt sırasında belirlenen minimum oksijen saturasyonu, homosistein, lipid profili (total kolesterol, $\mathrm{HDL}$, LDL, trigliserid) $\beta$-natriüretik peptid gibi parametreler ile korelasyonu olmadığı saptandı (Tablo 3a, 3b).

Gami ve ark.'nın, OUAS'ı 10701 hastada yaptıkları çalışmada; ortalama 5,3 yıllık takip sonrası ani kardiyak ölüm riskini $\% 0,27$ olarak bulmuşlardır. Ani kardiyak ölümdeki bağımsız risk faktörleri arasında; yaş, hipertansyion, koroner arter hastalığı, kardiyomyopati ya da kalp yetmezliği, ventriküler ektopi ya da stabil olmayan ventriküler taşikardi, düşük noktürnal oksijen saturasyonu göstermişlerdir (25). Ayrıca ani kardiyak ölüm için 60 yaş üstü olma, $\mathrm{AHI} ;>20$, ortalama O2 saturasyonu $<\% 93$

\begin{tabular}{|c|c|c|c|c|c|}
\hline \multicolumn{6}{|c|}{$\begin{array}{l}\text { Tablo 3b. Kardiyak repolarizasyon indeksinin diğer değişkenler ile } \\
\text { korelasyonu }\end{array}$} \\
\hline & $\mathrm{QT}_{\mathrm{D}}$ & AHI & Yaş & VKi & Min 02 \\
\hline $\mathrm{QT}_{\mathrm{D}}$ & 1 &, $247^{\star *}$ &,- 009 & 0,001 &,- 135 \\
\hline $\mathrm{AHI}$ &, $247^{* *}$ & 1 &, $203^{* *}$ & $415^{* *}$ &,$- 833^{\star *}$ \\
\hline Yaş &,- 009 &, $203^{* *}$ & 1 & 041 &,$- 191 *$ \\
\hline VKI & 0,001 &, $415^{\star \star}$ &, 041 & 1 &,$- 518^{\star \star}$ \\
\hline Min $\mathrm{O} 2$ &,- 135 &,$- 833^{* *}$ & $833^{* *}$ &,$- 518^{* *}$ & 1 \\
\hline
\end{tabular}

**Korelasyon 0,01 düzeyinde anlamlı, *Korelasyon 0,05 düzeyinde anlamlı, VKI: Vücut kitle indeksi 
ve minimum O2 saturasyonu < \%78 olarak belirlenmiştir (25). Bilindiği üzere QTD uzama ventriküler fibrilasyon ve ani kardiyak ölüm ile ilişkilidir. Bizim çalışmamızda da özellikle QTD uzamış olan hastaların yaş ortalamalarının $(p=0,05), A H I(p=0,0001)$, VKI $(0,0001)$, total trigliserid düzeylerinin $(0,015)$ istatistiksel olarak belirgin şekilde yüksek, minimum oksijen saturasyonların ise daha düşük $(0,0001)$ olduğu saptandı. Gami ve ark. gözlemsel çalışmasının elektrofizyolojik özellikte desteklendiği görülmektedir. Yine bu hastaların özellikle ağır OUAS hastaların devamlı pozitif hava akımı (CPAP) tedavisi kullandıktan sonra QTD azaldığı ya da bir başka deyiş ile normalize olduğu Dursunoğlu çalışmasında göstermiştir (26).

Çalışmada EKG parametreleri hastaların uyanık olduğu saatte çekilmiştir. Bu sonucun uyku sırasındaki ritim ile farklı olabilir mi düşünüldüğünde, Barta ve ark.'nın OUAS'lı hastalarda uyanıklık ve uyku sırasında kayıt edilen EKG verilerinde QT inerval ve QTD farklılık olmadığını göstermişlerdir, dolayısı ile bu hastalarda artmış kardiyak aritmi riskinin olmadığı vurgulanmıştır (27). Ancak Barta ve ark. çalışması küçük bir çalışma (25 hasta) grubunda yapılması çalışmanın dezavantajıdır. Bizim çalışmamızda 170 hastada elde edilen veriler uyanıklık EKG'de dahi hastaların QTD patoloji olduğunu göstermektedir. Ayrıca bilindiği üzere apne/hipopne ataklarının olduğu dönemde bradikardi ve taşikardi atakları, sempatik hiperaktivite ve otonomik disfonksiyon olduğu bilinmektedir. Bu şekli ile ağır uyku apne sendromu hastaların sadece uyku sırasında değil gün içi dönemde de aritmiye yatkın oldukları düşünülebilir.

Mclntyre ve ark., Padeletti ve ark., Voigt ve ark. çalışma ve derlemelerinde OUAS'lı hastalarda intermitant hipoksemi, uyanıklık reaksiyonları, sol ventriküler hipertofi, sempatik hiperaktivite OUAS hastalarda ani kardiyak ölüm için mekanizmalar olarak tanımlanmıştır $(24,28,29)$.

Çalışmamızda diğer anlamlı bulgu ise $\mathrm{AHI}$ arttıkça trigliserid düzeyinde anlamlı bir yükselme olurken homosistein, BNP serum düzeylerinde istatistiksel olarak anlamlı olmasa da yükselme olduğu görülmüştür. Bu açıdan bakıldığında, bizim çalışmamız nonspesifik biyokimyasal değerlerde değişiklik olmadan dahi kardiyak repolarizasyon indeksinde patolojik değişikliklerin olduğu görülmüştür.

\section{Kaynaklar}

1. Cortelli P, Lombardi C. Sleep and autonomic nervous system dysfunction. In: Clinical Neurophysiology of Sleep Disorders, Handbook of Clinical Neurophysiology Ed: C. Guilleminault. Elseiver. 2005;6:343-53.

2. Roche F, Xuong AN, Court-Fortune I, Costes F, Pichot V, Duverney D et al. Relationship among the severity of sleep apnea syndrome, cardiac arrhythmias, and autonomic imbalance. Pacing Clin Electrophysiol. 2003;26:669-77.

3. Dursunoğlu N, Dursunoğlu D. Obstructive sleep apnea syndrome, endothelial dysfunction and coronary atherosclerosis. Tuberk Toraks 2005;53:299-306.

4. Kraiczi H, Caidahl K, Samuelsson A, Peker Y, Hedner J. Impairment of vascular endothelial function and left ventricular filling: association with the severity of apnea-induced hypoxemia during sleep. Chest 2001;119:1085-91.

5. Ryan S, Nolan GM, Hannigan E, Cunningham S, Taylor C, McNicholas WT. Cardiovascular risk markers in obstructive sleep apnoea syndrome and correlation with obesity. Thorax 2007;62:509-14.

6. Kokturk O, Ciftci TU, Mollarecep E, Ciftci B. Elevated C-reactive protein levels and increased cardiovascular risk in patients with obstructive sleep apnea syndrome. Int Heart J 2005;46:801-9.

7. Aslan K, Deniz A, Cayli M, Bozdemir H, Sarica Y, Seydaoglu G. Early left ventricular functional alterations in patients with obstructive sleep apnea syndrome. Cardiol J 2013;20:519-25.

8. Miller WP. Cardiac arrhythmias and conduction disturbances in the sleep apnea syndrome. Prevalence and significance. Am J Med 1982;73:317-21.
9. Shahar E, Whitney CW, Redline S, Lee ET, Newman AB, Nieto FJ, et al. Sleep disordered breathing and cardiovascular diseases: crosssectional results of the Sleep Heart Health Study. Am J Respir Crit Care Med 2001;163:19-25.

10. Parati G, Lombardi C, Narkiewicz K. Sleep apnea: epidemiology, pathophysiology, and relation to cardiovascular risk. Am J Physiol Regul Integr Comp Physiol 2007;293:1671-83.

11. Maeder MT, Münzer T, Rickli H, Schoch OD, Korte W, Hürny $C$, et al. Association between heart rate recovery and severity of obstructive sleep apnea syndrome. Sleep Med. 2008;9:753-61. Epub 2007.

12. Çiçek D, Lakadamyali H, Gökay S, Sapmaz I, Muderrisoglu H. Effect of obstructive sleep apnea on heart rate, heart rate recovery and QTc and P-wave dispersion in newly diagnosed untreated patients. Am J Med Sci 2012;344:180-5.

13. Iber C, Ancoli-Israel, Chesson A; and Quan SF fort he American Academy of Sleep Medicine: The AASM Manual fort he Scoring of Sleep and Associated Events: Rules, Terminology and Technical Specifications, 1st ed.: Wectchester, Illınois: American Academy of Sleep Medicine, 2007.

14. Subbalakshmi NK, Adhikari PM, Sathyanarayana Rao KN, Jeganathan PS. Influencing factors of QTc among the clinical characteristics in type 2 diabetes mellitus. Diabetes Res Clin Pract 2010;88:265-72.

15. Correll CU, Frederickson AM, Figen V, Ginn-Scott EJ, Pantaleon Moya RA, Kane JM, et al. The QTc interval and its dispersion in patients receiving two atypical antipsychotics. Eur Arch Psychiatry Clin Neurosci 2009;259:23-7.

16. Henriksen JH, Gülberg V, Fuglsang S, Schifter S, Bendtsen F, Gerbes $\mathrm{AL}$, et al. Q-T interval (QT(C)) in patients with cirrhosis: relation to vasoactive peptides and heart rate. Scand J Clin Lab Invest 2007;67:643-53.

17. Johnson CD, Girod CE. Long Q-T interval and giant T wave inversion associated with complete atrioventricular block and bradycardia. Bol Asoc Med P R 2007;99:38-9.

18. Eckardt M, Gerlach L, Welter FL. Prolongation of the frequencycorrected QT dispersion following cerebral strokes with involvement of the insula of Reil. Eur Neurol 1999;42:190-3.

19. Mulcahy J, Johnson P, James M. Electrocardiogram QT interval increases in acute stroke. Cerebrovasc Dis 2010;29:178-80.

20. Lazar JM, Salciccioli L. Prognostic value of QT dispersion in acute stroke. Int J Cardiol 2008;129:1-2.

21. Calder K. QTc dispersion in intracerebral hemorrhage. Am J Emerg Med 2005;23:98.

22. Veglio M, Giunti S, Stevens LK, Fuller JH, Perin PC; EURODIAB IDDM Complications Study Group. Prevalence of Q-T interval dispersion in type 1 diabetes and its relation with cardiac ischemia : the EURODIAB IDDM Complications Study Group. Diabetes Care 2002;25:702-7.

23. Statters DJ, Malik M, Ward DE, Camm AJ. QT dispersion: problems of methodology and clinical significance. J Cardiovasc Electrophysiol 1994;5:672-85.

24. Padeletti M, Zacà V, Mondillo S, Jelic S. Sleep-disordered breathing increases the risk of arrhythmias. J Cardiovasc Med (Hagerstown) 2014; 15:411-6.

25. Gami AS, Olson EJ, Shen WK, Wright RS, Ballman KV, Hodge DO, et al. Obstructive sleep apnea and the risk of sudden cardiac death: a longitudinal study of 10,701 adults. J Am Coll Cardiol 2013;62:610-6.

26. Dursunoglu D, Dursunoglu N. Effect of CPAP on QT interval dispersion in obstructive sleep apnea patients without hypertension. Sleep Med 2007;8:478-83.

27. Barta K, Szabó Z, Kun C, Munkácsy C, Bene O, Magyar MT et al. The effect of sleep apnea on QT interval, QT dispersion, and arrhythmias. Clin Cardiol 2010;33:35-9.

28. Voigt L, Haq SA, Mitre CA, Lombardo G, Kassotis J. Effect of obstructive sleep apnea on QT dispersion: a potential mechanism of sudden cardiac death. Cardiology 2011;118:68-73.

29. WF Mclntyre, A Baranchuk, Sleep Disordered Breathing And Ventricular Arrhythmias: Mechanisms and Implications. ICRJ 2008;2:10-13. 